\title{
Design and Characterization of Bilayered Floating Tablets of Clopidogrel Bisulfate and Aspirin using Natural Gums
}

\author{
Manasa Reddy Devarapalli, Latha Kukati Latha*, Naseeb Basha Shaik, Shailaja Thoudoju, Saleha Fatima, Arshiya Sheerin, Mohammed \\ Atif Mujtaba, Shashanka Bhukya, Gaikwad Sushmitha \\ Department of Pharmaceutics, G. Pulla Reddy College of Pharmacy, Hyderabad, Telangana, INDIA.
}

\begin{abstract}
Objectives: In present investigation, an attempt was made to develop bilayered floating tablets of clopidogrel bisulfate and aspirin using natural gums as release retarded material. Clopidogrel bisulfate and aspirin are anti-platelet agents. Methodology: Clopidogrel bisulfate is a suitable candidate for formulating as gastro retentive dosage form as it has absorption window in stomach and solubility in the acidic pH. Sodium bicarbonate and citric acid were used to get desired floating properties. The effect of formulation variables on floating properties and drug release were investigated. Results: The tablets so designed were evaluated and found to have acceptable physicochemical properties, floating lag time, floating time and drug release. Among all the bilayered formulations, CBXA with susutained.release layer containing xanthan gum (2 ratio with drug), sodium bicarbonate $(15 \% \mathrm{w} / \mathrm{w})$ and citric acid $(1.2 \% \mathrm{w} / \mathrm{w})$ and immediate release layer containing sodium bicarbonate $(10 \% \mathrm{w} / \mathrm{w})$ and guar gum $(4 \% \mathrm{w} / \mathrm{w})$ has shown optimum results. Sustained release layer has shown dissolution of $99.03 \pm 0.42 \%$ in 12 hrs whereas immediate release layer has shown $99.4 \pm 0.44 \%$ in 30 mins.CBXA has shown optimum floating properties with in vitro floating lag time of $4 \mathrm{~min}$ and floating time of $>12 \mathrm{hr}$.
\end{abstract}

In vivo buoyancy study revealed that the floating time of CBXA was greater than $6 \mathrm{hr}$. The in vitro release data of optimized formulation was treated with mathematical equations and was evident that drug release followed zero order kinetics with case II transport mechanism. Conclusion: Based on the results it can be found that bilayered floating tablets of clopidogrel bisulfate and aspirin containing xanthan gum provides a better approach for sustained release and improved bioavailability.

Key words: Clopidogrel bisulfate, Bilayered floating tablets, Susutained release layer, Immediate release layer and Bioavailability.

Correspondence

Dr. K Latha, M. Pharm,

Professor, Department of Pharmaceutics, G. Pulla Reddy College of Pharmacy, Mehdipatnam, Hyderabad-28, Telangana, INDIA.

Phone: +919848630966

Email: lathakukati@gmail.com

DOI: 10.5530/jyp.2020.12s.41

\section{INTRODUCTION}

Concept of novel drug delivery system arose to overcome certain aspect related to physicochemical properties of drug and the related formulations. The important physiological factor which is responsible for the reduction in efficacy of oral formulations is gastric residence time (GRT). GRT considerably affects the bioavailability of the drug. Variable and short gastric emptying time results in incomplete drug release from oral formulations which leads to reduction in efficacy of the administered dose. GRT is affected by both the fasting as well as fed states of the stomach.

Gastroretentive systems are designed so that they are retained in the upper part of the gastrointestinal (GI) tract for several hours thereby prolong the gastric residence time of drugs. Floating systems or dynamically controlled systems are low-density systems that have sufficiently buoyancy to float over the gastric contents and remain buoyant in the stomach without affecting the gastric emptying rate for a prolonged period of time. This results in an increase in gastric retention time and a better control of fluctuation in plasma drug concentration..$^{1-4}$ Clopidogrel is a thienopyridine class inhibitor of P2Y12 adenosine 5 '-diphosphate (ADP) platelet receptors and used to inhibit blood clots in coronary artery disease, peripheral vascular disease and cerebrovascular disease. Clopidogrel is a pro-drug of carboxyl clopidogrel activated in the liver by cytochrome P450 and CYP2C19 enzyme. The active metabolite has an elimination half-life of about 7-8 h and acts by forming a disulfide bridge with the platelet ADP receptor. Following oral administration, it is well absorbed with bioavailability of about only $50 \%$ due to poor water solubility. The main side effects of the drug are gastric bleeding and clopidogrel drug resistance during chronic treatment. A sustained release floating clopidogrel formulation may be desired for several reasons, such as improving the bioavailability and to minimize the side effects of the drug such as gastric bleeding and to prevent the development of drug resistance wherefore to improve patient compliance.

Acetylsalicylic acid as an anti-inflammatory and anti-rheumatic agent may be due to inhibition of synthesis and release of prostaglandins. Acetylsalicylic acid appears to produce analgesia by virtue of both a peripheral and CNS effect. Peripherally, acetylsalicylic acid acts by inhibiting the synthesis and release of prostaglandins. Acetylsalicylic acid directly and irreversibly inhibits the activity of both types of cyclooxygenase (COX-1 and COX-2) to decrease the formation of precursors of prostaglandins and thromboxane from arachidonic acid..$^{5-8}$ The aim of the present study was to formulate and to characterize floating tablets of clopidogrel bisulphate and aspirin using the natural polymers such as guar gum, karaya gum, locust bean gum, xanthun gum, sodium bicarbonate, citric acid and PVPK-30 with increased bioavailability and sustained release.

\section{MATERIALS AND METHODS}

\section{Materials}

Clopidogrel bisulphate, aspirin, guar gum, karaya gum, locust bean gum, xanthun gum, sodium bicarbonate, citric acid and PVPK-30. 


\section{Experimental methods Preparation of formulation}

Development of bilayered floating tablets of clopidogrel bisulfate and aspirin were prepared using natural gums as release retarded material. Two layers such as immediate release (IR) layer and sustained release (SR) layer were formulated separately using different concentration of polymers in different ratios. After optimization of individual layers by in-vitro studies, bilayer tablets were prepared using optimized formula. Bilayer tablets were prepared on rotary tablet compression machine. First the extended release tablets were pre-compressed on compression machine manually and the immediate release layer was loaded on top of pre-compressed layer and punched.

\section{Evaluation parameters}

\section{Pre compression parameters}

All the flow properties were studied such as bulk density, tapped density, Carr's index, Hausner's ratio and angle of repose.

\section{Post compression parameters}

Bilayered floating tablets were evaluated for hardness, weight variation, friability and content uniformity. Sustained release floating layer was also evaluated for.

\section{Lag time}

The in vitro buoyancy was determined by the lag time. The tablets were placed in a $100 \mathrm{ml}$ beaker containing $0.1 \mathrm{~N} \mathrm{HCl}$. The time required for a tablet to rise to the surface for floating was determined as the lag time.

\section{Floating time}

The tablets were placed in a $100 \mathrm{ml}$ glass beaker containing $0.1 \mathrm{~N} \mathrm{HCl}$. The time required for which the tablet remained floating on the surface of medium was determined as floating time.

\section{Swelling index}

The swelling index of tablets was determined in $0.1 \mathrm{~N} \mathrm{HCl}$ at room temperature. The swollen weight of the tablets was determined at predefined time intervals. The swelling index was calculated by the following equation. Determinations were made in triplicate.

$$
\% \text { Swelling Index }=\frac{\mathrm{W}_{\mathrm{t}}-\mathrm{W}_{0}}{\mathrm{~W}_{\mathrm{t}}} \times 100
$$

Where, $\mathrm{W}_{0}$ is the initial weight of tablet, $\mathrm{W}_{\mathrm{t}}$ is the weight of the tablet at time.

\section{RESULTS AND DISCUSSIONS}

\section{Analytical method development for clopidogrel bisulfate and aspirin \\ Scan for absorption maxima $\left(\lambda_{\max }\right)$ of clopidogrel bisulfate and aspirin}

The analytical method development for clopidogrel bisulfate and aspirin were performed for the determination of absorption maxima using $10 \mu \mathrm{g} / \mathrm{ml}$ of standard solution on a double beam spectrophotometer against $0.1 \mathrm{~N} \mathrm{HCl}$ as the blank.

\section{Drug-excipients compatibility study by FTIR}

From IR spectra shown in the Figure 1,2 and 3 the peaks representing the pure drugs were similar in all the graphs suggesting that there are no interactions and the pure drugs were not altered functionally.

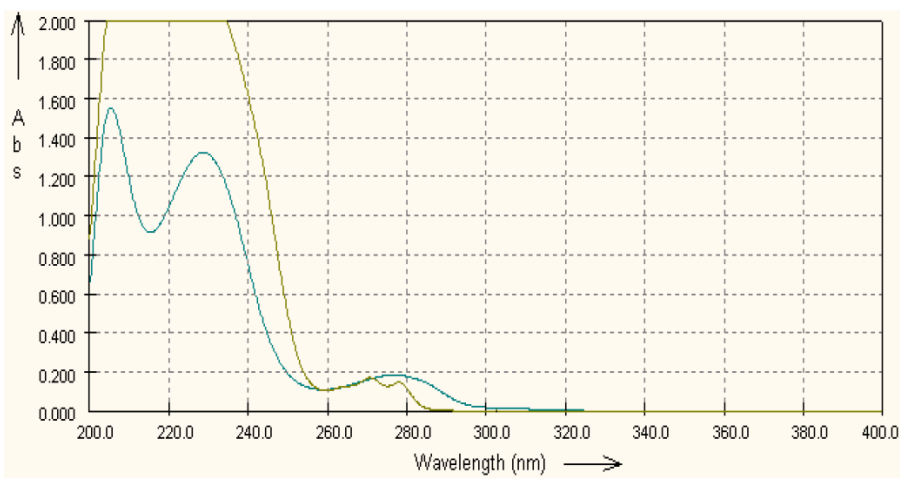

Figure 1: Spectral scan of clopidogrel bisulfate and aspirin.

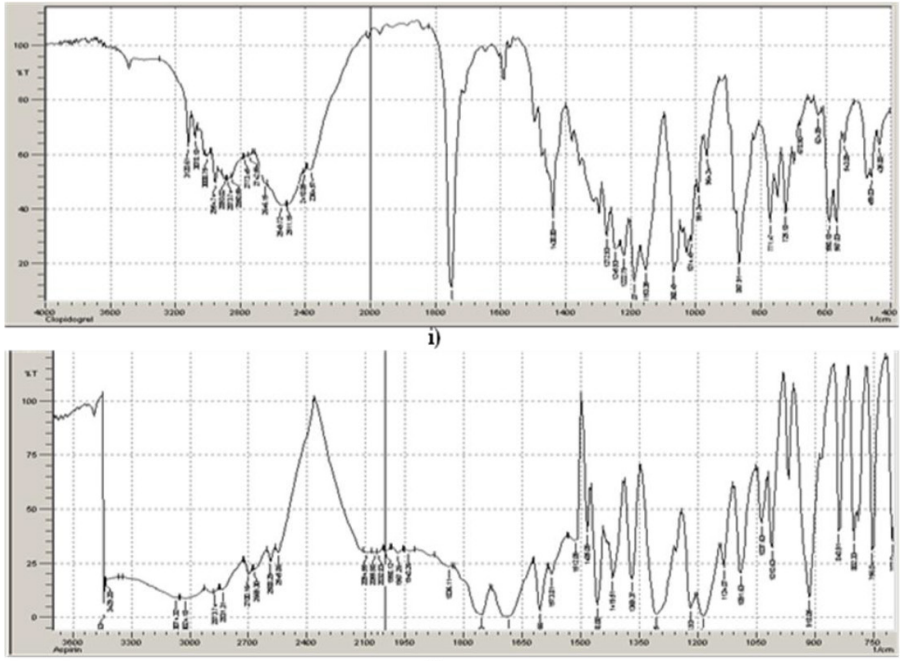

ii)

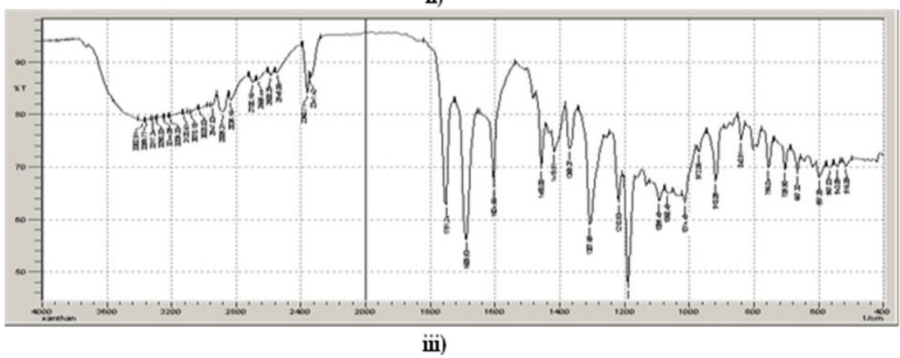

Figure 2: FTIR spectra of i) Clopidogrel bisulfate ii) Xanthan gum iii) Clopidogrel bisulfate +Xanthan gum.

\section{Pre compression parameters}

It was found that the Angle of repose, Hausner's ratio and Carr's index of clopidogrel bisulfate and the its powder blends were in the range of 44.92 to $53.3^{\circ}, 1.32$ to $1.46 \mathrm{gm} / \mathrm{cm}^{3}$ and 22.46 to $29.67 \%$ respectively as shown in the Table 1 . This indicates that they do not possess required flow characteristics for direct compression. ${ }^{8}$ Hence sustained release clopidogrel bisulfate layer was prepared by using .wet.granulation. Whereas aspirin has shown angle of repose, hausner's ratio and Carr's index values of $31.2^{\circ}, 1.15 \mathrm{gm} / \mathrm{cm}^{3}$ and $13.38 \%$ respectively. This indicates that aspirin have enough flow properties for direct compression.

From Table 2 Angle of repose, Hausner's ratio and Carr's Index was found in the range of $30.21-38.9^{\circ}, 0.66-0.79 \mathrm{gm} / \mathrm{cm}^{3}$ and $8.9-14.9 \%$ which indicates that granules of all the formulations possess good flow properties. ${ }^{8}$ 

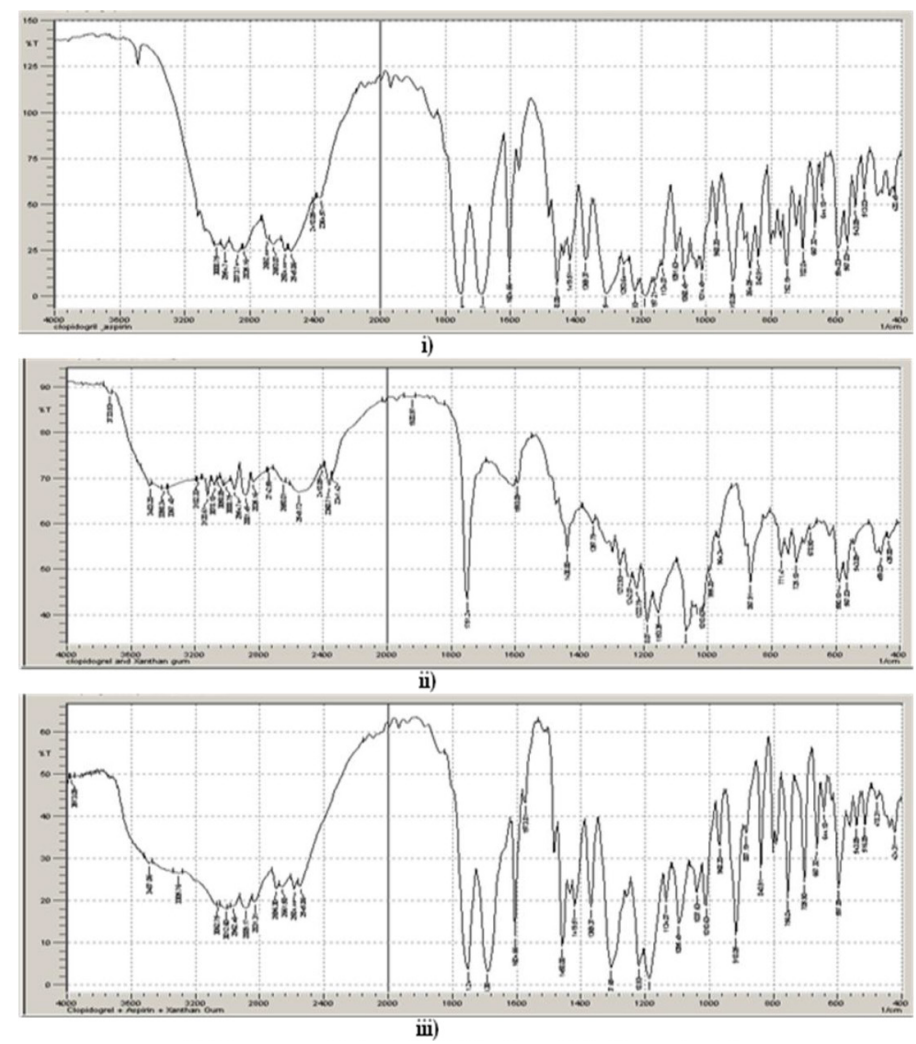

Figure 3: FTIR spectra of i) Aspirin ii) Clopidogrel bisulfate + Aspirin iii) Clopidogrel bisulfate + Aspirin +xanthan gum.

\section{EVALUATION OF TABLETS}

Prepared floating tablets were evaluated for physiochemical properties. The hardness of clopidogrel bisulfate sustained release tablets was found to be in the range of 6.7 to $7.05 \mathrm{~kg} / \mathrm{cm}^{2}$. The thickness of the tablets was found to be in the range of 4.08 to $4.18 \mathrm{~mm}$. Weight variation, friability and drug content were in the range of 385 to $400 \mathrm{mg}, 0.1$ to $0.52 \%$ and 94 to $99.3 \%$ respectively as shown in the Table 3 . Thus all the parameters of the tablets were within compendial standards. ${ }^{8}$

The hardness of clopidogrel bisulfate sustained release tablets was found to be in the range of 6.78 to $7.12 \mathrm{~kg} / \mathrm{cm}^{2}$. The thickness of the tablets was found to be in the range of 4 to $4.17 \mathrm{~mm}$. Weight variation, friability and drug content were in the range of 378 to $392 \mathrm{mg}, 0.1$ to $0.43 \%$ and 94 to $99.6 \%$ respectively as shown in the Table 4 . Thus all the parameters of the tablets were within compendial standards. ${ }^{9-11}$

The hardness of aspirin immediate release tablets was found to be in the range of 3 to $3.2 \mathrm{~kg} / \mathrm{cm}^{2}$. The thickness of the tablets was found to be in the range of 2.08 to $2.24 \mathrm{~mm}$. Weight variation, friability and drug content were in the range of 242 to $249 \mathrm{mg}, 0.38$ to $0.68 \%$ and 95.86 to $98.1 \%$ respectively. All the formulations have shown disintegration

Table 1: Pre compression parameters of the powder blends.

\begin{tabular}{cccc} 
Ingredients & Angle of repose & Hausner's ratio & $\begin{array}{c}\text { Carr's index } \\
(\%)\end{array}$ \\
\hline Clopidogrel bisulfate & $53.3 \pm 0.54$ & $1.40 \pm 0.093$ & $29.67 \pm 0.22$ \\
CB+ karaya gum & $44.92 \pm 0.13$ & $1.32 \pm 0.041$ & $22.46 \pm 0.15$ \\
CB+ xanthan gum & $50 \pm 0.49$ & $1.46 \pm 0.027$ & $24.1 \pm 0.17$ \\
Aspirin & $31.265 \pm 3.9$ & $1.15 \pm 0.035$ & $13.38 \pm 0.33$ \\
\hline
\end{tabular}

Table 2: Pre compression parameters of the granules.

\begin{tabular}{|c|c|c|c|c|c|}
\hline CODE & Angle of repose & Bulk density $\left(\mathrm{gm} / \mathrm{cm}^{3}\right)$ & Tapped density $\left(\mathrm{gm} / \mathrm{cm}^{3}\right)$ & Hausner's ratio & Carr's Index (\%) \\
\hline CBK1 & $32.05 \pm 0.12$ & $0.75 \pm 0.016$ & $0.84 \pm 0.02$ & $1.12 \pm 0.05$ & $10.93 \pm 0.09$ \\
\hline CBK2 & $37.26 \pm 0.19$ & $0.73 \pm 0.063$ & $0.80 \pm 0.014$ & $1.01 \pm 0.016$ & $12.32 \pm 0.014$ \\
\hline CBK3 & $30.21 \pm 0.22$ & $0.79 \pm 0.034$ & $0.86 \pm 0.04$ & $1.09 \pm 0.053$ & $11.15 \pm 0.018$ \\
\hline CBK4 & $36.74 \pm 0.37$ & $0.73 \pm 0.023$ & $0.84 \pm 0.014$ & $1.15 \pm 0.055$ & $10.27 \pm 0.025$ \\
\hline CBK5 & $38.63 \pm 0.18$ & $0.71 \pm 0.07$ & $0.79 \pm 0.015$ & $1.11 \pm 0.049$ & $11.285 \pm 0.07$ \\
\hline CBK6 & $37.06 \pm 0.05$ & $0.7 \pm 0.05$ & $0.75 \pm 0.056$ & $1.07 \pm 0.079$ & $13.38 \pm 0.082$ \\
\hline CBK7 & $34.33 \pm 0.27$ & $0.73 \pm 0.022$ & $0.78 \pm 0.01$ & $1.07 \pm 0.033$ & $14.65 \pm 0.031$ \\
\hline CBK8 & $35.54 \pm 0.44$ & $0.79 \pm 0.09$ & $0.84 \pm 0.09$ & $1.05 \pm 0.012$ & $9.785 \pm 0.047$ \\
\hline CBK9 & $37.95 \pm 0.96$ & $0.72 \pm 0.06$ & $0.79 \pm 0.03$ & $1.09 \pm 0.05$ & $11.345 \pm 0.07$ \\
\hline CBK10 & $37.36 \pm 0.43$ & $0.71 \pm 0.011$ & $0.74 \pm 0.073$ & $1.03 \pm 0.01$ & $13.88 \pm 0.014$ \\
\hline CBK11 & $36.26 \pm 0.34$ & $0.68 \pm 0.51$ & $0.77 \pm 0.8$ & $1.13 \pm 0.12$ & $11.55 \pm 0.23$ \\
\hline CBX1 & $36.63 \pm 0.18$ & $0.7 \pm 0.025$ & $0.75 \pm 0.012$ & $1.06 \pm 0.034$ & $8.9 \pm 0.14$ \\
\hline $\mathrm{CBX} 2$ & $36.36 \pm 0.72$ & $0.72 \pm 0.033$ & $0.81 \pm 0.018$ & $1.12 \pm 0.038$ & $10.65 \pm 0.23$ \\
\hline CBX3 & $37.27 \pm 0.8$ & $0.75 \pm 0.065$ & $0.78 \pm 0.05$ & $1.03 \pm 0.022$ & $11.39 \pm 0.07$ \\
\hline CBX4 & $38.63 \pm 0.97$ & $0.66 \pm 0.03$ & $0.71 \pm 0.07$ & $1.08 \pm 0.05$ & $10.57 \pm 0.51$ \\
\hline CBX5 & $36.55 \pm 0.14$ & $0.66 \pm 0.062$ & $0.7 \pm 0.024$ & $1.06 \pm 0.09$ & $13.78 \pm 0.27$ \\
\hline CBX6 & $37.67 \pm 0.56$ & $0.68 \pm 0.09$ & $0.74 \pm 0.013$ & $1.09 \pm 0.063$ & $11.84 \pm 0.19$ \\
\hline $\mathrm{CBX} 7$ & $38.92 \pm 0.42$ & $0.75 \pm 0.023$ & $0.83 \pm 0.045$ & $1.1 \pm 0.035$ & $14.89 \pm 0.15$ \\
\hline CBX8 & $38.47 \pm 0.69$ & $0.67 \pm 0.094$ & $0.74 \pm 0.015$ & $1.1 \pm 0.023$ & $14.37 \pm 0.055$ \\
\hline СBX9 & $35.76 \pm 0.3$ & $0.72 \pm 0.089$ & $0.80 \pm 0.03$ & $1.12 \pm 0.05$ & $13.39 \pm 0.038$ \\
\hline CBX10 & $38.95 \pm 0.42$ & $0.76 \pm 0.033$ & $0.87 \pm 0.056$ & $1.14 \pm 0.049$ & $11.33 \pm 0.16$ \\
\hline CBX11 & $37.15 \pm 0.57$ & $0.7 \pm 0.01$ & $0.78 \pm 0.012$ & $1.1 \pm 0.037$ & $11.75 \pm 0.12$ \\
\hline CBX12 & $38.32 \pm 0.48$ & $0.68 \pm 0.081$ & $0.72 \pm 0.014$ & $1.05 \pm 0.022$ & $9.65 \pm 0.037$ \\
\hline CBX13 & $37.49 \pm 0.32$ & $0.75 \pm 0.016$ & $0.84 \pm 0.02$ & $1.11 \pm 0.05$ & $10.95 \pm 0.09$ \\
\hline
\end{tabular}

Note: All the values are expressed as Mean $\pm \mathrm{SD}, n=3$ 
Devarapalli, et al.: Design and Characterization of Bilayered Floating Tablets of Clopidogrel Bisulfate and Aspirin using Natural Gums

Table 3: Physiochemical evaluations of clopidogrel bisulfate matrix tablets.

\begin{tabular}{|c|c|c|c|c|c|}
\hline Code & Hardness $\left(\mathrm{kg} / \mathrm{cm}^{2}\right)^{\mathrm{a}}$ & Thickness $(\mathrm{mm})^{\mathrm{b}}$ & Weight variation (\%) & Friability $(\%)^{d}$ & Drug content (\%) \\
\hline CBK1 & $6.77 \pm 0.26$ & $4.1 \pm 0.056$ & $389 \pm 3.1$ & $0.25 \pm 0.07$ & $98 \pm 0.9$ \\
\hline CBK2 & $6.94 \pm 0.25$ & $4.13 \pm 0.059$ & $398 \pm 0.2$ & $0.37 \pm 0.011$ & $98.7 \pm 0.18$ \\
\hline CBK3 & $6.26 \pm 0.23$ & $4.02 \pm 0.091$ & $400 \pm-0.1$ & $0.39 \pm 0.018$ & $99.3 \pm 0.94$ \\
\hline CBK4 & $7.05 \pm 0.25$ & $4.19 \pm 0.063$ & $387 \pm 0.96$ & $0.3 \pm 0.017$ & $95.3 \pm 0.91$ \\
\hline CBK5 & $7 \pm 0.16$ & $4.08 \pm 0.08$ & $399 \pm 0.17$ & $0.34 \pm 0.098$ & $95.3 \pm 0.82$ \\
\hline CBK6 & $7.03 \pm 0.15$ & $4.09 \pm 0.044$ & $385 \pm 1.35$ & $0.52 \pm 0.04$ & $95.3 \pm 0.9$ \\
\hline CBK7 & $6.96 \pm 0.27$ & $4.2 \pm 0.055$ & $392 \pm 1.7$ & $0.14 \pm 0.018$ & $96 \pm 0.88$ \\
\hline CBK8 & $6.95 \pm 0.26$ & $4.18 \pm 0.067$ & $395 \pm 0.8$ & $0.27 \pm 0.019$ & $99.6 \pm 0.97$ \\
\hline CBK9 & $7 \pm 0.26$ & $4.05 \pm 0.08$ & $386 \pm 1.2$ & $0.32 \pm 0.036$ & $94 \pm 0.84$ \\
\hline CBK10 & $7.05 \pm 0.16$ & $4.03 \pm 0.074$ & $391 \pm 0.57$ & $0.3 \pm 0.019$ & $98 \pm 0.94$ \\
\hline CBK11 & $6.99 \pm 0.22$ & $4.08 \pm 0.068$ & $393 \pm 0.15$ & $0.16 \pm 0.032$ & $97.3 \pm 0.8$ \\
\hline
\end{tabular}

Note: All the values are expressed as Mean \pm SD. $a, b: n=5, c: n=20$, $d$, e: $n=10$

Table 4: Physiochemical evaluations of clopidogrel bisulfate matrix tablets.

\begin{tabular}{|c|c|c|c|c|c|}
\hline Code & Hardness $\left(\mathrm{kg} / \mathrm{cm}^{2}\right)^{\mathrm{a}}$ & Thickness $(\mathrm{mm})^{\mathrm{b}}$ & Weight variation (\%) & Friability (\%) ${ }^{d}$ & Drug content (\%) \\
\hline CBX1 & $6.97 \pm 0.01$ & $4.1 \pm 0.017$ & $385 \pm 0.021$ & $0.4 \pm 0.019$ & $98.9 \pm 0.14$ \\
\hline CBX2 & $7.04 \pm 0.025$ & $4.07 \pm 0.02$ & $381 \pm 0.028$ & $0.32 \pm 0.037$ & $99.3 \pm 0.94$ \\
\hline СВX3 & $7.05 \pm 0.022$ & $4.01 \pm 0.06$ & $388 \pm 0.053$ & $0.23 \pm 0.017$ & $97.3 \pm 1.9$ \\
\hline CBX4 & $7.07 \pm 0.013$ & $4.06 \pm 0.024$ & $391 \pm 0.027$ & $0.43 \pm 0.018$ & $95.3 \pm 0.9$ \\
\hline CBX5 & $7.02 \pm 0.023$ & $4.03 \pm 0.062$ & $397 \pm 0.073$ & $0.31 \pm 0.036$ & $94 \pm 0.81$ \\
\hline СBX6 & $7 \pm 0.024$ & $4.11 \pm 0.039$ & $384 \pm 0.051$ & $0.14 \pm 0.018$ & $97.3 \pm 0.94$ \\
\hline CBX7 & $6.78 \pm 0.019$ & $4.05 \pm 0.023$ & $383 \pm 0.077$ & $0.39 \pm 0.017$ & $97.3 \pm 0.19$ \\
\hline CBX8 & $6.96 \pm 0.019$ & $4.1 \pm 0.034$ & $394 \pm 0.015$ & $0.15 \pm 0.098$ & $99.3 \pm 0.9$ \\
\hline СвХ9 & $7.2 \pm 0.068$ & $4.12 \pm 0.046$ & $380 \pm 0.03$ & $0.24 \pm 0.019$ & $97.3 \pm 1.4$ \\
\hline CBX10 & $7.04 \pm 0.023$ & $4.04 \pm 0.033$ & $387 \pm 0.078$ & $0.17 \pm 0.01$ & $95.6 \pm 0.37$ \\
\hline CBX11 & $6.95 \pm 0.022$ & $4.17 \pm 0.05$ & $378 \pm 0.02$ & $0.1 \pm 0.02$ & $97.6 \pm 0.32$ \\
\hline CBX12 & $7.12 \pm 0.013$ & $4.08 \pm 0.037$ & $392 \pm 0.034$ & $0.28 \pm 0.054$ & $96.7 \pm 0.47$ \\
\hline CBX13 & $7.02 \pm 0.02$ & $4.15 \pm 0.016$ & $384 \pm 0.02$ & $0.26 \pm 0.05$ & $95.3 \pm 0.68$ \\
\hline
\end{tabular}

Note: All the values are expressed as Mean \pm SD. a, b: $n=5$, c: $n=20$, d, e: $n=10$

Table 5: Physiochemical evaluations of immediate release tablets.

\begin{tabular}{cccccc}
\hline Code & Hardness $\left(\mathbf{k g} / \mathrm{cm}^{2}\right)^{\mathrm{a}}$ & ${\text { Thickness }(\mathrm{mm})^{\mathrm{b}}}$ & Weight variation (\%) $^{\mathrm{c}}$ & Friability (\%) $^{\mathrm{d}}$ & ${\text { Drug content }(\%)^{\mathrm{e}}}^{\text {Disintegration }(\text { Mins })^{\mathrm{f}}}$ \\
\hline A1 & $3.2 \pm 0.017$ & $2.1 \pm 0.045$ & $243 \pm 0.87$ & $0.45 \pm 0.016$ & $97.84 \pm 0.45$ \\
A2 & $3.14 \pm 0.029$ & $2.15 \pm 0.061$ & $247 \pm 0.71$ & $0.38 \pm 0.028$ & $95.86 \pm 0.57$ \\
A3 & $3 \pm 0.021$ & $2.08 \pm 0.086$ & $242 \pm-0.68$ & $0.58 \pm 0.018$ & $97.6 \pm 0.90$ \\
A4 & $3.07 \pm 0.013$ & $2.24 \pm 0.021$ & $249 \pm 0.26$ & $0.68 \pm 0.06$ & $96.06 \pm 0.91$ \\
A5 & $3.12 \pm 0.031$ & $2.17 \pm 0.016$ & $248 \pm 0.17$ & $0.42 \pm 0.014$ & $98.14 \pm 0.22$ \\
A6 & $3.17 \pm 0.024$ & $2.13 \pm 0.02$ & $243 \pm 0.5$ & $0.54 \pm 0.017$ & $97.45 \pm 0.55$ \\
A7 & $3.11 \pm 0.019$ & $2.19 \pm 0.03$ & $243 \pm 0.26$ & $0.65 \pm 0.06$ & $96.13 \pm 0.56$ \\
A8 & $3.09 \pm 0.013$ & $2.17 \pm 0.041$ & $247 \pm 0.15$ & $0.52 \pm 0.016$ & $97.06 \pm 0.42$ \\
A9 & $3.21 \pm 0.068$ & $2.13 \pm 0.016$ & $245 \pm 0.53$ & $0.48 \pm 0.08$ & $97.8 \pm 0.51$ \\
\hline
\end{tabular}

Note: All the values are expressed as Mean \pm SD. a, b: $n=5$, c: $n=20$, d, e: $n=10$, f: $n=6$

Table 6: Physiochemical evaluations of bilayered floating tablets.

\begin{tabular}{|c|c|c|c|c|c|}
\hline Code & Hardness $\left(\mathrm{kg} / \mathrm{cm}^{2}\right)^{\mathrm{a}}$ & Thickness $(\mathrm{mm})^{\mathrm{b}}$ & Weight variation $(\%)^{c}$ & Friability $(\%)^{d}$ & Drug content (\%) \\
\hline CBKA & $6.4 \pm 0.23$ & $5.89 \pm 0.15$ & $648 \pm 0.7$ & $0.16 \pm 0.4$ & $97.6 \pm 0.41$ \\
\hline CBXA & $6.34 \pm 0.19$ & $5.77 \pm 0.2$ & $643 \pm 0.6$ & $0.23 \pm 0.6$ & $98.96 \pm 0.6$ \\
\hline
\end{tabular}

Note: All the values are expressed as Mean \pm SD. a, b: $n=5, c: n=20$, d, e: $n=10$ 
Table 7: Floating lag time and floating time of sustained release tablets (Karaya gum).

\begin{tabular}{ccc}
\hline CODE & Floating lag time (min.) & Floating time (hrs) \\
\hline CBK1 & 35 & 6 \\
CBK2 & 38 & 10 \\
CBK3 & 47 & 8 \\
CBK4 & 51 & 10 \\
CBK5 & 41 & NO INTEGRITY \\
CBK6 & 33 & NO INTEGRITY \\
CBK7 & 20 & 11 \\
CBK8 & 5 & NO INTEGRITY \\
CBK9 & 2 & NO INTEGRITY \\
CBK10 & 21 & $>12$ \\
CBK11 & 11 & 8 \\
\hline
\end{tabular}

Table 8: Floating lag time and floating time of sustained release tablets (Xanthan gum).

\begin{tabular}{ccc}
\hline CODE & Floating lag time (mins) & Floating time (hrs) \\
\hline CBX1 & 28 & 8 \\
CBX2 & 28 & 10 \\
CBX3 & 40 & 11 \\
CBX4 & 43 & 10 \\
CBX5 & 39 & NO INTEGRITY \\
CBX6 & 25 & NO INTEGRITY \\
CBX7 & 17 & 9 \\
CBX8 & 4 & 11 \\
CBX9 & 3 & NO INTEGRITY \\
CBX10 & 19 & 10 \\
CBX11 & 3 & NO INTEGRITY \\
CBX12 & 7 & $>12$ \\
CBX13 & 6 & NO INTEGRITY \\
\hline
\end{tabular}

less than 6 mins as shown in the Table 5. Among all the formulations A3 have shown less disintegration time. Thus all the parameters of the tablets were within compendial standards.

The hardness of bilayered floating tablets was found to be in the range of 6.34 to $6.4 \mathrm{~kg} / \mathrm{cm}^{2}$. The thickness of the tablets was found to be in the range of 5.77 to $5.89 \mathrm{~mm}$. Weight variation, friability and drug content were in the range of 643 to $648 \mathrm{mg}, 0.16$ to $0.23 \%$ and 97.6 to $98.96 \%$ respectively as shown in the Table 6 . Thus all the parameters of the tablets were within compendial standards.

\section{In vitro buoyancy}

Buoyancy test was conducted for the formulations CBK1 to CBK11. Among these formulations CBK7, CBK8, CBK9, CBK10, CBK11 have shown lag time less than $30 \mathrm{~min}$ as shown in the Table 7.

Buoyancy test was conducted for the formulations CBK1 to CBK11 and CBX1 to CBX13 as shown in the Table 8.

Buoyancy test was conducted for the formulations CBK1 to CBK11 and CBX1 to CBX13.Among these formulations CBK7, CBK8, CBK9, CBK10, CBK11, CBX1, СBX2, СВX6, СBX7, СВX8, СВX9, СВX10, CBX11, CBX12, CBX13 have shown lag time less than 30 mins. But,
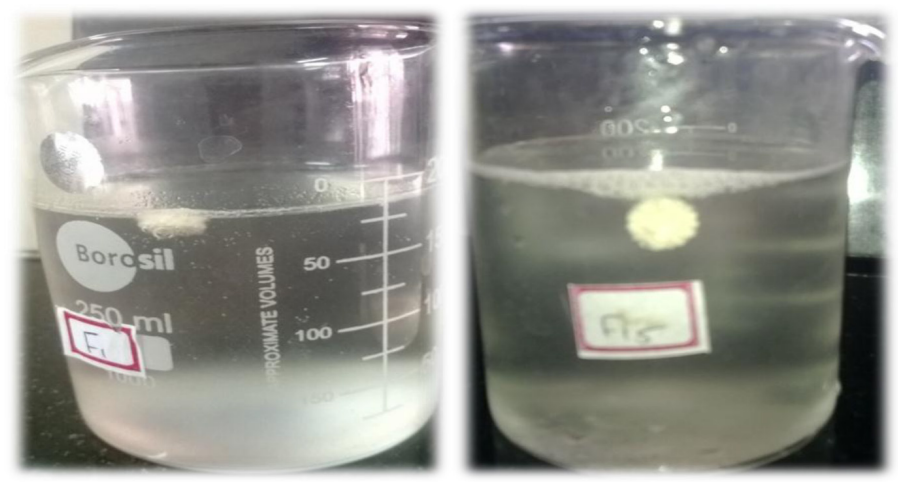

Figure 4: In-vitro buoyancy of optimized formulation.

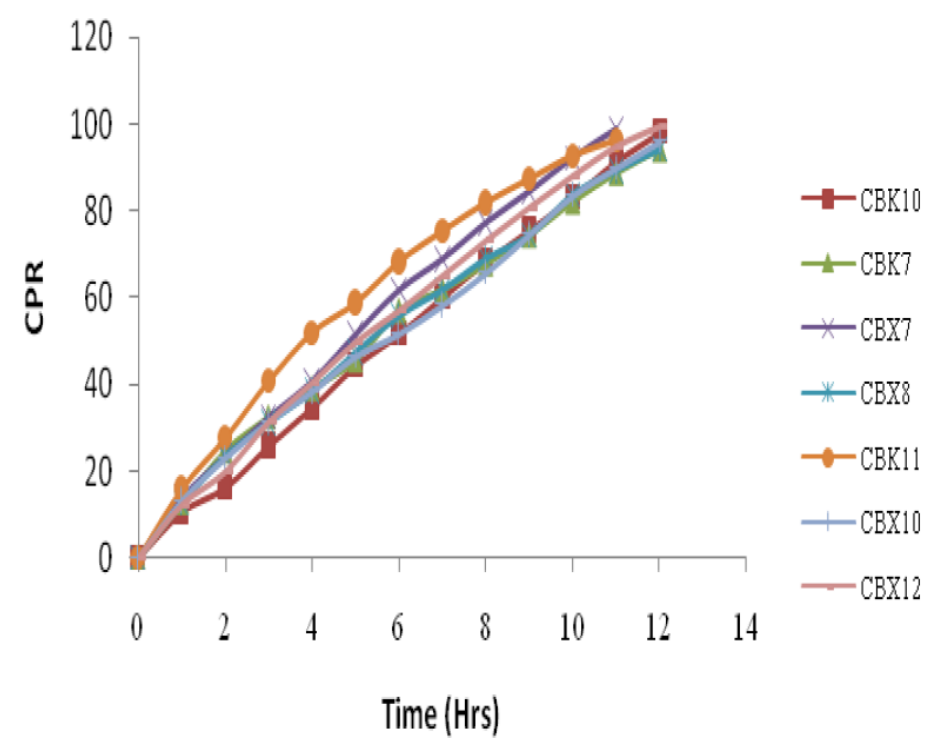

Figure 5: Dissolution profiles of different formulations.

formulations $\mathrm{CBK} 8, \mathrm{CBK} 9, \mathrm{CBX} 6, \mathrm{CBX} 9, \mathrm{CBX} 11, \mathrm{CBX} 13$ have lost integrity though they have shown floating lag time less than 30 mins. So, formulations CBK7, CBK10, CBK11, CBX1, CBX2, CBX7, CBX8, CBX10, CBX12 were selected and subjected to dissolution studies for optimization. Figure 4 indicates in vitro buoyancy of CBX12

\section{In vitro drug dissolution testing of floating table}

It was observed that increasing the amount of karaya gum in the formulation, resulted in slower rate and decreased amount of drug release from the tablet. This slow release is because of the formation of more thick gel like structure around karaya gum that delays release from tablet matrix and retarding further penetration of dissolution medium, prolong the drug release. Among all the formulations CBK10 has shown maximum drug release i.e. $98 \%$ over a period of $12 \mathrm{~h}$ as shown in the Table 9 and Figure 5, 6 and 7.

It was observed that increasing the amount of gum in the formulation, resulted in slower rate and decreased amount of drug release from the tablet. Comparison between xanthan gum and karaya gum based tablets, release of drug from xanthan gum based tablet was found to be more slowly compared to karaya gum based tablet. This slow release is because of the formation of more thick gel like structure around the matrix of xanthan gum compared to karaya gum that delays release from tablet matrix and retarding further penetration of dissolution medium, prolong 
Table 9: Dissolution profiles of sustained release matrix tablets (Karaya gum).

\begin{tabular}{|c|c|c|c|c|c|c|c|}
\hline \multirow[t]{2}{*}{ TIME (hrs) } & \multicolumn{7}{|c|}{ \%Drug release } \\
\hline & CBK1 & CBK2 & CBK3 & CBX4 & CBK7 & CBK10 & CBK11 \\
\hline 1 & $13.8 \pm 0.96$ & $15.6 \pm 0.21$ & $13.2 \pm 0.13$ & $10.2 \pm 0.74$ & $12.6 \pm 0.54$ & $10.5 \pm 0.4$ & $15.9 \pm 0.49$ \\
\hline 2 & $25.8 \pm 0.79$ & $29.4 \pm 0.62$ & $24.6 \pm 0.74$ & $18.6 \pm 0.18$ & $24.6 \pm 0.85$ & $16.1 \pm 0.14$ & $27.5 \pm 1.7$ \\
\hline 3 & $38.4 \pm 0.06$ & $43.2 \pm 0.77$ & $31.8 \pm 0.74$ & $28.2 \pm 0.13$ & $32.4 \pm 0.69$ & $25.8 \pm 0.16$ & $40.68 \pm 1.2$ \\
\hline 4 & $51 \pm 0.83$ & $54 \pm 0.64$ & $39 \pm 0.18$ & $36.6 \pm 0.68$ & $39 \pm 0.84$ & $34.6 \pm 0.25$ & $51.8 \pm 0.7$ \\
\hline 5 & $60.6 \pm 0.67$ & $63.6 \pm 0.4$ & $47.4 \pm 0.53$ & $45.7 \pm 0.43$ & $45.6 \pm 0.39$ & $44.2 \pm 2.38$ & $58.6 \pm 0.83$ \\
\hline 6 & $67.2 \pm 0.35$ & $69.6 \pm 0.96$ & $56.4 \pm 0.31$ & $54.6 \pm 0.29$ & $57 \pm 0.85$ & $51.5 \pm 0.35$ & $68.1 \pm 0.04$ \\
\hline 7 & $83.4 \pm 0.56$ & $75 \pm 0.61$ & $61.8 \pm 0.27$ & $60.6 \pm 0.48$ & $61.8 \pm 0.81$ & $60.1 \pm 0.02$ & $75.2 \pm 0.37$ \\
\hline 8 & $90.6 \pm 0.37$ & $81.6 \pm 0.29$ & $67.8 \pm 0.45$ & $66.6 \pm 0.97$ & $67.8 \pm 0.54$ & $68.3 \pm 0.19$ & $81.8 \pm 0.15$ \\
\hline 9 & $96.1 \pm 0.88$ & $86.4 \pm 0.71$ & $75.6 \pm 0.32$ & $72.6 \pm 0.83$ & $74.4 \pm 0.69$ & $75.5 \pm 0.11$ & $87.2 \pm 0.1$ \\
\hline 10 & - & $91.8 \pm 0.42$ & $83.4 \pm 0.19$ & $77.4 \pm 0.28$ & $82.2 . \pm 0.5$ & $83.1 . \pm 0.13$ & $92.5 \pm 0.09$ \\
\hline 11 & - & $96.6 \pm 0.42$ & $89.4 \pm 0.2$ & $81.6 \pm 0.57$ & $88.8 \pm 0.69$ & $91.5 \pm 0.48$ & $96 \pm 0.26$ \\
\hline 12 & - & - & $95.4 \pm 0.46$ & $84.6 \pm 0.24$ & $94.2 . \pm 0.24$ & $98 . \pm 0.24$ & - \\
\hline
\end{tabular}

Note: All the values are expressed as mean $\pm \mathrm{SD}, \mathrm{n}=3$

Table 10: Dissolution profiles of sustained release matrix tablets (Xanthan gum).

\begin{tabular}{|c|c|c|c|c|c|c|c|c|}
\hline \multirow[t]{2}{*}{ TIME (hrs) } & \multicolumn{8}{|c|}{$\%$ Drug release } \\
\hline & $\mathrm{CBX} 1$ & CBX2 & CBX3 & CBKX4 & CBX7 & CBX8 & CBX10 & CBX12 \\
\hline 1 & $12.6 \pm 0.38$ & $12.1 \pm 0.95$ & $9.71 \pm 0.63$ & $7.3 \pm 0.12$ & $13.8 \pm 2.5$ & $12.6 \pm 0.84$ & $13.2 \pm 0.43$ & $12.2 \pm 0.04$ \\
\hline 2 & $23.4 \pm 0.46$ & $23.4 \pm 0.63$ & $17.4 \pm 54$ & $13.8 \pm 0.75$ & $23.4 \pm 0.85$ & $23.4 \pm 0.84$ & $23 \pm 0.03$ & $19.8 \pm 0.3$ \\
\hline 3 & $35.3 \pm 0.39$ & $31.3 \pm 0.07$ & $25.8 \pm 0.25$ & $20.1 \pm 0.62$ & $32.4 \pm 1.69$ & $31.2 \pm 0.00$ & $31.4 \pm 0.44$ & $31.3 \pm 0.3$ \\
\hline 4 & $46.7 \pm 0.98$ & $40.2 \pm 0.32$ & $33.1 \pm 0.32$ & $26.4 \pm 0.55$ & $40.8 \pm 1.7$ & $38.4 \pm 1.69$ & $38.3 \pm 0.73$ & $40.3 \pm 0.28$ \\
\hline 5 & $56.4 \pm 0.54$ & $48.6 \pm 0.15$ & $40.2 \pm 0.66$ & $31.5 \pm 0.81$ & $51.6 \pm 0.39$ & $47.4 \pm 2.55$ & $46.4 \pm 0.26$ & $49.6 \pm 0.51$ \\
\hline 6 & $64.2 \pm 0.78$ & $55.8 \pm 0.64$ & $47.41 \pm 0.85$ & $37.2 \pm 0.42$ & $61.8 \pm 0.54$ & $55.8 \pm 0.85$ & $51.6 \pm 0.5$ & $56.84 \pm 0.19$ \\
\hline 7 & $73.3 \pm 0.24$ & $62.4 \pm 0.41$ & $54.67 \pm 0.3$ & $45.6 \pm 0.13$ & $69 \pm 0.84$ & $61.8 \pm 0.85$ & $58.2 \pm 0.21$ & $64.9 \pm 0.2$ \\
\hline 8 & $81.1 \pm 0.77$ & $69.8 \pm 0.2$ & $60.9 \pm 0.57$ & $50.1 \pm 0.27$ & $77.4 \pm 0.54$ & $69 \pm 0.85$ & $65.6 \pm 0.2$ & $73 \pm 0.14$ \\
\hline 9 & $89.4 \pm 0.72$ & $75.6 \pm 0.62$ & $67.8 \pm 0.38$ & $56.4 \pm 0.78$ & $84.6 \pm 0.85$ & $74.4 \pm 1.7$ & $74.5 \pm 0.39$ & $80.7 \pm 0.47$ \\
\hline 10 & $97.2 \pm 0.5$ & $82.2 \pm 0.57$ & $72.6 \pm 0.22$ & $63.8 \pm 0.95$ & $92.4 \pm 0.69$ & $83.8 \pm 1.7$ & $83.5 \pm 0.67$ & $87.9 \pm 0.27$ \\
\hline 11 & - & $89.4 \pm 0.77$ & $77.3 \pm 0.91$ & $66.7 \pm 0.77$ & $99 \pm 0.84$ & $89.4 \pm 0.85$ & $89.9 \pm 0.16$ & $94.7 \pm 0.26$ \\
\hline 12 & - & $94.1 \pm 0.16$ & $82.2 \pm 0.71$ & $72.7 \pm 0.12$ & - & $94.2 \pm 0.85$ & $95.9 \pm 0.1$ & $99.3 \pm 0.08$ \\
\hline
\end{tabular}

Note: All the values are expressed as mean $\pm \mathrm{SD}, n=3$

the drug release. ${ }^{11}$ Among all the xanthan gum based formulations, CBX12 has shown the maximum drug release of $99.3 \%$ over a period of 12 as shown in the Table 10.

Among all the formulations of immediate release aspirin layer formulation A4 with 5\% sodium bicarbonate and 3\% guar gum was optimized as it has shown release within 30 mins $^{12}$ as shown in the Table 11.

In bilayered tablet, Sustained release matrix layer with 1:2 ratio of clopidogrel bisulfate: xanthan gum has shown $99.03 \pm 0.42$ release in 12 hrs whereas immediate release layer with $5 \%$ sodium bicarbonate and 3\% guar gum has shown $99.4 \pm 0.44 \%$ release within $30 \mathrm{~min}^{13-16}$ as Table 12 and Figure 8.

\section{Drug release kinetics}

Model dependent Method: Drug release profiles of all the formulations into zero order release model, first order release model, Higuchi model and korsmeyer-peppas model as the Table 13.

Based on the results of model dependent kinetic analysis of dissolution profiles of formulation CBXA, it was found that the release of the drug

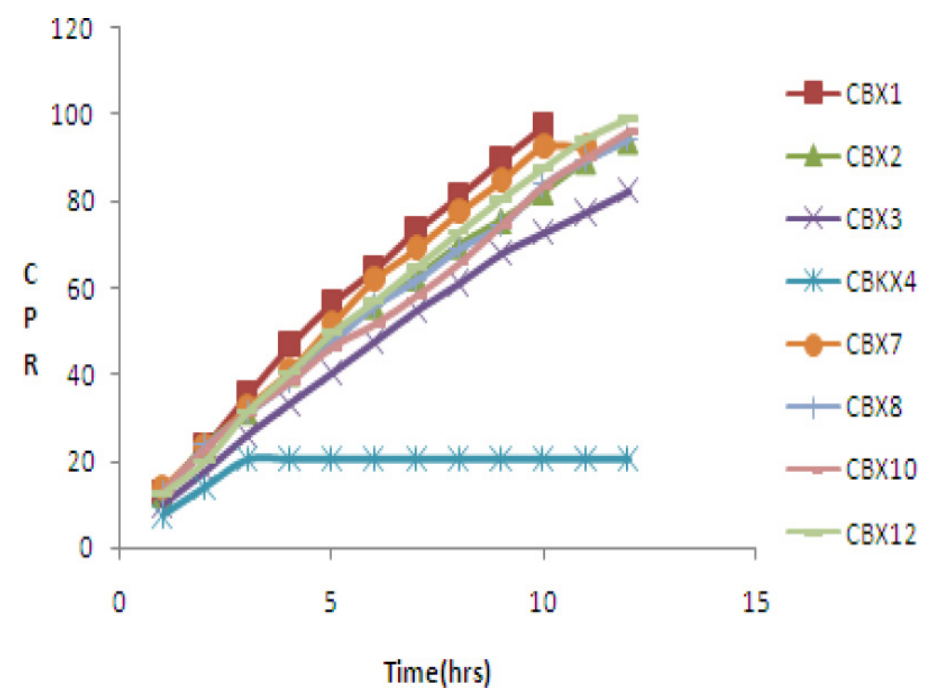

Figure 6: Dissolution profiles of different formulations. 
Table 11: Dissolution profiles of immediate release tablets.

\begin{tabular}{ccccccccc}
\hline \multirow{2}{*}{ TIME (hrs) } & \multicolumn{9}{c}{ \%Drug release } \\
\cline { 2 - 9 } & A4 & A5 & A6 & A7 & A8 & A9 & CBX10 & CBX12 \\
\hline 5 & $23.1 \pm 0.54$ & $15.7 \pm 0.9$ & $14.2 \pm 0.18$ & $24.5 \pm 0.36$ & $24.5 \pm 0.36$ & $15.2 \pm 0.54$ & $13.2 \pm 0.43$ & $12.2 \pm 0.04$ \\
10 & $41.1 \pm 0.36$ & $28.3 \pm 0.72$ & $23.7 \pm 0.36$ & $38.4 \pm 0.54$ & $38.4 \pm 0.54$ & $29.2 \pm 0.18$ & $23 \pm 0.03$ & $19.8 \pm 0.3$ \\
15 & $57.2 \pm 0.72$ & $43.9 \pm 0.36$ & $38.9 \pm 1.2$ & $51.3 \pm 0.36$ & $30.38 \pm 0.7$ & $44 \pm 0.18$ & $31.4 \pm 0.44$ & $31.3 \pm 0.3$ \\
20 & $72.3 \pm 0.18$ & $56 \pm 0.18$ & $47.5 \pm 0.36$ & $63.7 \pm 0.18$ & $41.5 \pm 0.54$ & $56.7 \pm 0.36$ & $38.3 \pm 0.73$ & $40.3 \pm 0.28$ \\
25 & $85 \pm 0.72$ & $67.2 \pm 0.18$ & $54.4 \pm 0.00$ & $73.8 \pm 0.39$ & $50 \pm 0.36$ & $66.9 \pm 0.72$ & $46.4 \pm 0.26$ & $49.6 \pm 0.51$ \\
30 & $95.6 \pm 0.9$ & $79.7 \pm 0.36$ & $64.7 \pm 0.9$ & $92 \pm 0.54$ & $59.7 \pm 0.00$ & $77.6 \pm 0.36$ & $51.6 \pm 0.5$ & $56.84 \pm 0.19$ \\
40 & - & $95.5 \pm 0.72$ & $74.3 \pm 0.7$ & $99.6 \pm 0.36$ & $76.6 \pm 0.7$ & $96.1 \pm 0.5$ & $58.2 \pm 0.21$ & $64.9 \pm 0.2$ \\
50 & - & - & $89 \pm 0.18$ & - & $94.6 \pm 0.18$ & - & $65.6 \pm 0.2$ & $73 \pm 0.14$ \\
60 & - & - & $97.7 \pm 0.54$ & - & - & - & $74.5 \pm 0.39$ & $80.7 \pm 0.47$ \\
\hline
\end{tabular}

Note: All the values are expressed as mean \pm SD, $n=3$

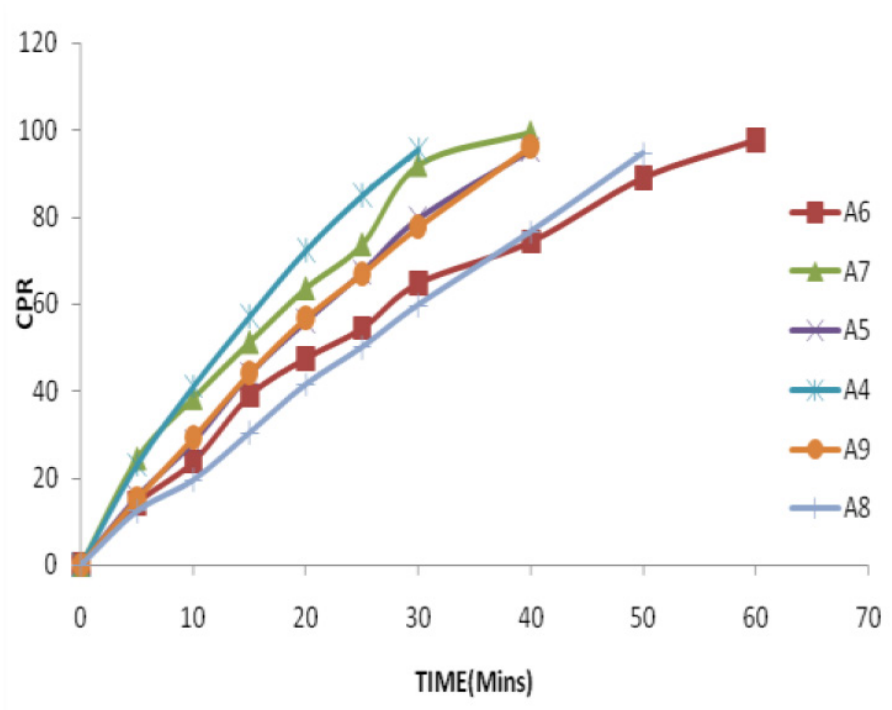

Figure 7: Dissolution profiles of different immediate release formulations.

Table 12: Dissolution profiles of optimized bilayered tablet.

\begin{tabular}{cccc}
\hline Time (Hrs) & $\begin{array}{c}\text { \% Drug release of } \\
\text { sustained release } \\
\text { matrix layer }\end{array}$ & Time (Min.) & $\begin{array}{c}\text { \% Drug release of } \\
\text { immediate release } \\
\text { layer }\end{array}$ \\
\hline 1 & $14 \pm 0.28$ & 5 & $26.04 \pm 0.4$ \\
2 & $22.4 \pm 0.07$ & 10 & $48 \pm 0.95$ \\
3 & $30.5 \pm 0.6$ & 15 & $62.8 \pm 0.6$ \\
4 & $37.1 \pm 0.03$ & 20 & $77.7 \pm 0.7$ \\
5 & $46.4 \pm 0.09$ & 25 & $89.3 \pm 0.17$ \\
6 & $54.4 \pm 0.5$ & 30 & $99.4 \pm 0.44$ \\
7 & $61.2 \pm 0.08$ & - & - \\
8 & $68.9 \pm 0.37$ & - & - \\
9 & $75.6 \pm 0.1$ & - & - \\
10 & $84.7 \pm 1.6$ & - & - \\
11 & $92.5 \pm 0.46$ & - & - \\
12 & $99.03 \pm 0.42$ & - & - \\
\hline
\end{tabular}

Note: All the values are expressed as mean $\pm \mathrm{SD}, n=3$

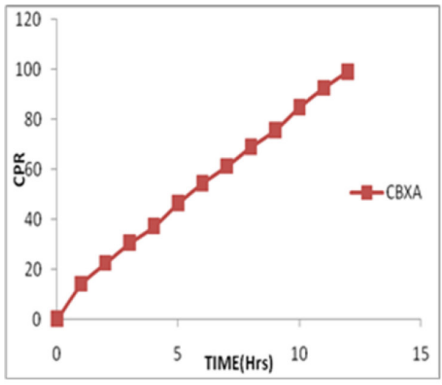

(a)

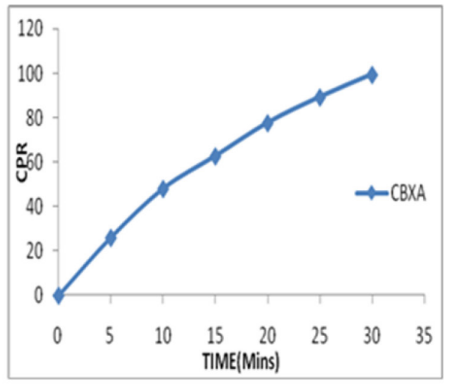

(b)
Figure 8: Dissolution profiles of $C B X A$ a) Sustain release b) Immediate release.

from these formulations followed zero order kinetics and mechanism of release was found to be case II transport as shown in the Table 14. Indicates model dependant kinetics of CBX12.

\section{In vivo Buoyancy Study}

In vivo buoyancy study was performed on healthy rabbit. The animal dose was calculated using dose translation based on Body Surface Area (BSA). From the obtained results it was observed bilayered floating tablets (CBXA) remained in the gastric region for $6 \mathrm{hr}$ of administration indicating good retention of the tablets in the stomach region.

Figure 9 indicates position of bilayered floating tablet at different time intervals. In vivo floating time was greater than 6 hrs as shown in the Figure 9 i, ii, iii, iv whereas after 6 hrs floating ability of tablet was lost as shown in the Figure $9 \mathrm{v}$.

\section{STABILITY STUDIES}

Optimized formulation was subjected for stability studies. Based on the results it can be concluded that, optimized tablets were stable during accelerated stability studies, with insignificant change in the floating lag time, floating time, drug content and in vitro drug release characteristics as shown in the Figure 10.

\section{CONCLUSION}

Bilayered floating matrix tablets of clopidogrel bisulfate and aspirin can be formulated as an approach to increase gastric residence time and thereby improving its bioavailability. Sustained release matrix layer of clopidogrel bisulfate was been prepared using guar gum, karaya gum, 
Devarapalli, et al.: Design and Characterization of Bilayered Floating Tablets of Clopidogrel Bisulfate and Aspirin using Natural Gums

Table 13: Model dependent kinetics of sustained release formulations.

\begin{tabular}{|c|c|c|c|c|c|c|}
\hline \multirow{2}{*}{ CODE } & \multirow{2}{*}{$\frac{\text { Zero order }}{R^{2}}$} & \multirow{2}{*}{$\frac{\text { First order }}{R^{2}}$} & \multirow{2}{*}{$\begin{array}{c}\text { Higuchi } \\
R^{2}\end{array}$} & \multicolumn{2}{|c|}{ Korsmeyer-Peppas } & \multirow{2}{*}{ Release Mechanism } \\
\hline & & & & $R^{2}$ & $\mathrm{n}$ & \\
\hline CBK1 & 0.991 & 0.82 & 0.99 & 0.98 & 0.89 & Case II transport \\
\hline CBK2 & 0.951 & 0.79 & 0.99 & 0.93 & 0.74 & Anomalous transport \\
\hline CBK3 & 0.991 & 0.55 & 0.91 & 0.83 & 0.71 & Anomalous transport \\
\hline CBK4 & 0.980 & 0.76 & 0.97 & 0.95 & 0.77 & Anomalous transport \\
\hline CBK7 & 0.998 & 0.9 & 0.91 & 0.98 & 0.78 & Anomalous transport \\
\hline CBK10 & 0.998 & 0.84 & 0.97 & 0.96 & 0.61 & Anomalous transport \\
\hline CBK11 & 0.992 & 0.93 & 0.94 & 0.99 & 0.78 & Anomalous transport \\
\hline $\mathrm{CBX} 1$ & 0.989 & 0.97 & 0.71 & 0.95 & 1.75 & Super case II transport \\
\hline $\mathrm{CBX} 2$ & 0.992 & 0.92 & 0.94 & 0.99 & 0.539 & Anomalous transport \\
\hline CBX3 & 0.993 & 0.97 & 0.95 & 0.97 & 1.18 & Super case II transport \\
\hline $\mathrm{CBX} 4$ & 0.997 & 0.98 & 0.82 & 0.93 & 1.37 & Super case II transport \\
\hline CBX7 & 0.994 & 0.78 & 0.98 & 0.85 & 1.34 & Super case II transport \\
\hline CBX8 & 0.991 & 0.81 & 0.98 & 0.87 & 1.87 & Super case II transport \\
\hline CBX10 & 0.994 & 0.86 & 0.97 & 0.89 & 1.48 & Super case II transport \\
\hline $\mathrm{CBX} 12$ & 0.993 & 0.97 & 0.84 & 0.88 & 1.57 & Super case II transport \\
\hline
\end{tabular}

Table 14: Model dependent kinetic analysis of optimized bilayered formulation

\begin{tabular}{ccccccc}
\hline \multirow{2}{*}{ CODE } & Zero order & First order & Higuchi & \multicolumn{2}{c}{ Korsmeyer- Peppas } \\
\cline { 2 - 6 } & $R^{2}$ & $R^{2}$ & $R^{2}$ & $R^{2}$ & Release Mechanism \\
\hline CBKA & 0.991 & 0.871 & 0.98 & 0.972 & 0.73 & Anomalous transport \\
CBXA & 0.999 & 0.925 & 0.91 & 0.993 & 0.89 & Case II transport \\
\hline
\end{tabular}

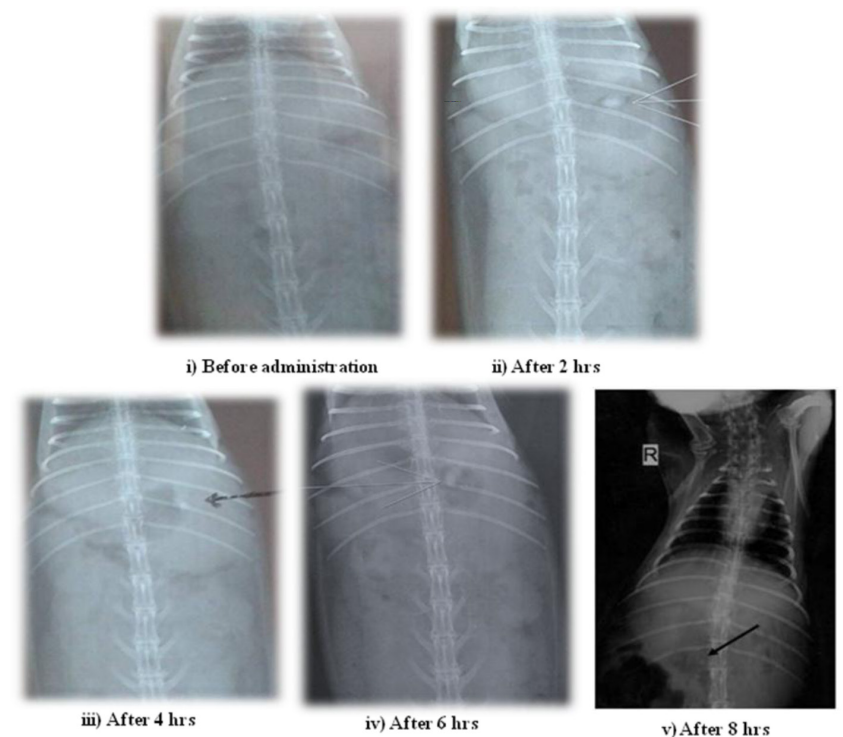

Figure 9: X-ray photographs of GIT of rabbit at different time intervals after administration of bilayered floating tablet.

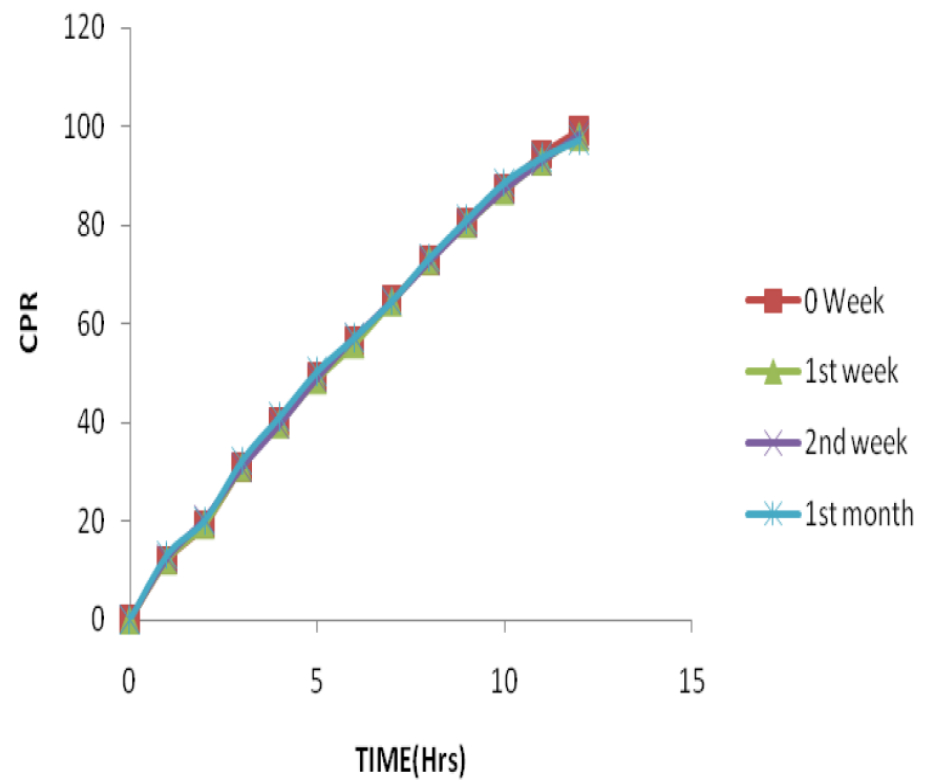

Figure 10: Percentage drug release of optimized formulation during ASS. 
locust bean gum and xanthan gum as rate control polymers, sodium bicarbonate and citric acid as gas generating agents. Immediate release layer of aspirin have been prepared using sodium bicarbonate as disintegrant and PVP K-30, guar gum and gum acacia as binders. Among all the bilayered formulations, CBXA with susutained release layer containing xanthan gum (2 ratio with drug), sodium bicarbonate $(15 \% \mathrm{w} / \mathrm{w})$ and citric acid $(1.2 \% \mathrm{w} / \mathrm{w})$ and immediate release layer containing sodium bicarbonate $(10 \% \mathrm{w} / \mathrm{w})$ and guar gum $(4 \% \mathrm{w} / \mathrm{w})$ has shown optimum results. Sustained release layer has shown dissolution of $99.03 \pm 0.42 \%$ in $12 \mathrm{hr}$ whereas immediate release layer has shown $99.4 \pm 0.44 \%$ in $30 \mathrm{~min}$. CBXA has shown optimum floating properties with in vitro floating lag time of $4 \mathrm{~min}$ and floating time of $>12 \mathrm{hr}$. In vivo buoyancy study revealed that floating time is greater than $6 \mathrm{hr}$. Based on the results of model dependent kinetic analysis of CBXA, it was found that the release of the drug followed zero order kinetics and mechanism of release was found to be case II transport.

\section{ACKNOWLEDGEMENT}

The authors are thankful to principal and management of G. Pulla Reddy College of Pharmacy, Hyderabad for providing facilities to conduct our research.

\section{CONFLICT OF INTEREST}

Authors declare that there is no conflict of interest.

\section{ABBREVIATIONS}

GRT: Gastric Residence Time; GI tract: Gastro Intestinal; COX: CycloOxygenase; IR: Immediate Release; SR: Sustained Release; FTIR: Fourier Transfer InfraRed; BSA: Body Surface Area.

\section{REFERENCES}

1. Agmar K, Michael B, Wolfgang M, Stephan S. Effect of coadministration of rivaroxaban and clopidogrel on bleeding time. Pharmacodynamics and Pharma- cokinetics: A phase I Study, Pharmaceuticals. 2012;5(3):279-96.

2. Ajay KP, Ashish P, Ramya D, Sharanya K, Alekhya P. Formulation and evaluation of sustained release matrix tablets of nicorandil. International Journal of Applied Biology and Pharmaceutical Technology. 2011;2(3):242-6.

3. Ashok AH, Vrushali AP. Formulation and Characterization of Metformin Hydrochloride Floating tablets. Asian Pharma Press. 2012;2(3):111-7.

4. Bhupendra GP, Satish NP. Formulation, evaluation and optimization of orally disintegrating tablet of cinnarizine. E: Journal of Science and Technology. 2010;5(5):9-21.

5. Dayakar B, Sriram NA, Eswar KD, Sai K. Design and in vitro dissolution of metoprolol succinate floating tablets. Asian Journal of Pharmaceutical Research. 2013;3(1):1-8.

6. Jaldhara SP, Divya T, Kalpen NP, Ketan JP. A review on bilayer tablets. Journal of Drug Discovery and Therapeutics. 2013;1(3):40-8.

7. Jaleh $V$, Naser T, Fatemeh K. Use of Hydrophilic natural gums in formulation of sustained-release matrix tablets of tramadol hydrochloride. American Association of Pharmaceutical Sciences. 2006;7(1):1-7.

8. Jigar AP, Jiitendra SP, Arjun S, Hemangi JP. Formulation and evaluation of immediate release tablet of azithromycin by dry granulation method using super disintegrants. American Journal of Pharmtech Research. 2011;1(4):211-8.

9. Kiran KP, Subash V, Narsimha RY. Clopidogrel: An overview. International Journal of Pharmacology Research. 2013;3(1):1-7.

10. Mathew VMD, Richard FL. Aspirin-Exacerbated Asthma. Allergy, Asthma and Clinical Immunology. 2008;4(2):75-83

11. Varshosaz J, Emami J, Jafari E. Comparison of hydrophilic natural gums and cellulosic polymers in formulation of sustained-release matrix tablets of terbutalin sulfate. Reasearch in Pharmaceutical Sciences. 2006;1(1):30-9.

12. Nagesh C, Attimarad SL, Kugaji MS, Shreenal PV. Design and in vitro evaluation of gastroretentive drug delivery system of carvedilol. Semanticscholar Conference Proceedings. 2013.

13. Roberta R, Giuseppe M, Tamar N, Antonello G. Clopidogrel bisulfate: A Review of its Use in the management of acute coronary syndrome. Clinical Medicine: Therapeutics. 2009;1(1):899-910.

14. Ofori-kwakye K, Osei-yeboah F, Samuel LK. Formulation and quality evaluation of two conventional release tablet formulations. International Journal of Pharmaceutical Sciences Review and Research. 2010;4(1):94-9.

15. Vinoth KM, Krishnarajan R, Manivannan R, Parthiban KG. Formulation and evaluation of bi-layer domperidone floating tablets. linternational Journal of Pharmaceutical Research and Science. 2011;2(8):2217-25.

16. Marvola M, Hannula AM, Ojantakanen S, Westermarck E, Rajamäki M. Effect of sodium bicarbonate and sodium starch glycolate on the in vivo disintegration of hard gelatin capsules: A radiological study in the dog. Acta Pharmaceutica. 1989;1(6):355-62. 